NASA Technical Memorandum 88981

\title{
Deformation and Fracture of Single-Crystal and Sintered Polycrystalline Silicon Carbide Produced by Cavitation
}

\author{
(NASA-TH-88981) DEFOFEATICN AND FRACTURE OF \\ SINGLE-CEYSTAL INL SINTERED ECLYCEYSTALLINE \\ N87-20422 \\ SILICCA CARBILE EFCDUCED EI CAVITATION \\ (NASA) $25 \mathrm{p}$ \\ CSCL $20 B$ \\ G3/27 Unclas 45320
}

Kazuhisa Miyoshi

Lewis Research Center

Cleveland, Ohio

Shuji Hattori and Tsunenori Okada

Fukui University

Fukui, Japan

Donald H. Buckley

Case Western Reserve University

Cleveland, Ohio

Prepared for the

1987 Joint Tribology Conference

cosponsored by the American Society of Lubrication Engineers

and the American Society of Mechanical Engineers

San Antonio, Texas, October 5-8, 1987

\section{Rnsh}


DEFORMATION AND FRACTURE OF SINGLE-CRYSTAL AND SINTERED POLYCRYSTALLINE

\title{
SILICON CARBIDE PRODUCED BY CAVITATION
}

\author{
Kazuhisa Miyoshi* \\ National Aeronautics and Space Administration \\ Lewis Research Center \\ Cleveland, Ohio 44135 \\ Shuji Hattori and Tsunenori Okada \\ Fukui University \\ Fukui, Japan \\ and \\ Donald H. Buckley* \\ Case Western Reserve University \\ Cleveland, Ohio 44106
}

SUMMARY

An investigation was conducted to examine the deformation and fracture behavior of single-crystal and sintered polycrystalline SiC surfaces exposed to cavitation. Cavitation erosion experiments were conducted in distilled water at $25^{\circ} \mathrm{C}$ by using a magnetostrictive oscillator in close proximity (1 $\mathrm{mm}$ ) to the surface of SiC. The horn frequency was $20 \mathrm{kHz}$, and the double amplitude of the vibrating disk was $50 \mu \mathrm{m}$. The results of the investigation indicate that the SiC $\{0001\}$ surface could be deformed in a plastic manner during cavitation. Dislocation etch pits were formed when the surface was chemically etched. The number of defects, including dislocations in the Sic \{0001\} surface, increased with increasing exposure time to cavitation.

The presence of intrinsic defects such as voids in the surficial layers of the sintered polycrystalline SiC determined the zones at which fractured grains and fracture pits (pores) were generated. Single-crystal sic had superior erosion resistance to that of sintered polycrystalline SiC.

*Member, ASLE. 


\section{INTRODUCTION}

Lubrication is extremely important to ceramic materials in tribological systems. Lubricants reduce not only adhesion, friction, and wear of ceramic materials, but also brittle fracture during sliding, which is one of the main limitations to a wider use of ceramic materials in tribological applications (1). However, in lubricated systems cavitation erosion may occur on a surface of ceramic components such as ceramic bearings. The recurring impact pressure due to the repeated formation and collapse of cavitation bubbles in lubricant film may result in mechanical fatigue of the bearing and erosion on the bearing surface. Indeed, a past study of cavitation erosion, which used a laboratory vibratory cavitation apparatus on magnesium oxide, has indicated that considerable plastic deformation occurred on the MgO surface and that the crystalline state of the eroded surfaces was changed drastically during cavitation (2).

The objective of this paper is to examine the deformation and fracture behavior of single-crystal and sintered polycrystalline a-sic surfaces exposed to cavitation. Cavitation erosion experiments were conducted in distilled water at $25^{\circ} \mathrm{C}$ by using a magnetostrictive oscillator system operating at a frequency of $20 \mathrm{kHz}$.

Etching has been a useful tool for investigating dislocation densities and plastic deformation in ceramics (2-6). Therefore etch pitting was used in the present investigation to study the near-surface deformation processes in Sic resulting from cavitation erosion. Optical and scanning electron microscopy, and surface profilometry were also used for the surface analyses of the SiC specimens. There are some inherent limitations in using a mechanical stylus to measure the profile of the eroded surfaces of single-crystal and sintered polycrystalline sic. For example, because the stylus has a radius it is very difficult to follow the true surface profile 
for surfaces containing sharp hills or valleys (5). Nevertheless, surface profilometry is still a useful tool not only for detecting fracture pits, but also for characterizing eroded surfaces of single-crystal and sintered polycrystalline SiC. Further, such studies could provide a much-needed understanding of the erosion behavior and the possible deformation and fracture mechanisms of interesting and potentially useful structural ceramics such as SiC.

\section{MATERIALS}

The single-crystal a-SiC used in the experiments was 99.9 percent pure (table 1). The crystal was grown by a carbon arc method. The $\{0001\}$ basal plane of the single-crystal SiC was parallel to the surfaces examined herein. The SiC specimens were in the form of flat platelets.

The sintered polycrystalline $\alpha$-SiC used in the experiments was 98.5 to 98.7 at $x$ pure (table 1). An average grain size of $9 \mu \mathrm{m}$ was obtained by measuring 40 grains of polycrystalline SiC in scanning electron micrographs. Also, SiC grains have prismlike shapes with sharp edges. Because of these irregularly shaped grains, two dimensions (the largest diameter and smallest diameter of each of the SiC grains) were also measured from scanning electron photomicrographs.

The $\alpha$-SiC has a hexagonal close-packed crystal structure. The most commonly occurring unit cell dimensions were secondary axes $a=0.30817 \mathrm{~nm}$ and primary axis $C=1.51183 \mathrm{~nm}(7)$. The unit cell contains two interpenetrating, close-packed atomic arrays - one of silicon and the other of carbon displaced by one-quarter of a layer spacing along the C-axis. Thus the stlicon atoms occupy the tetrahedral locations in the arrays of carbon atoms, and the carbon aioms occupy the tetrahedral locations in the arrays of silicon atoms (8), (9). 
An ultrasonic magnetostrictive oscillator was used in this investigation tu generate cavitation in liquids (Fig. 1). With a booster placed between the converter and the oscillating horn, a maximum amplitude of $105 \mu \mathrm{m}$ with a maximum output power of $450 \mathrm{~W}$ could be achieved. The SiC specimens were mounted on the specimen holder in close proximity to the vibrating disk screwed into the oscillating horn. The oscillator had a sinusoidal motion at $20 \mathrm{kHz}$ during the experiment. This cyclic motion resulted in the formation of low pressure and, hence, cavitation between the specimen surface and the disk during part of the cycle. The cavitating bubbles imploded and attacked the specimen surface under the high pressure formed during the remaining part of the cycle.

\section{EXPERIMENTAL PROCEDURE}

The surfaces of the single-crystal and the sintered polycrystalline sic used in the cavitation erosion experiments were polished with diamond powder (1-um particle diameter). The back of each specimen was attached to a specimen holder. The specimens were then placed in the apparatus. All the SiC surfaces were rinsed with pure ethyl alcohol and then with distilled water before being placed in the cavitation erosion apparatus. The separation distance of $1 \mathrm{~mm}$ between the vibrating disk and SiC specimen was set by a micrometer. Cavitation erosion experiments were conducted with a double amplitude of the vibrating disk of $50 \mu \mathrm{m}$ in distilled water at $25^{\circ} \mathrm{C}$.

Molten salt was used for etch pitting. A fused anhydrous sodium carbonate $\left(\mathrm{Na}_{2} \mathrm{CO}_{3}\right)$ contained in a platinum crucible held at approximately $950{ }^{\circ} \mathrm{C}$ for 3 min was used to reveal dislocations on the $\{0001\}$ surface of SiC (10). The etching was followed by light repolishing with $\mathrm{Al}_{2}{ }_{3}$ powder (1-um particle diameter). An approximate etch rate of $0.3 \mu \mathrm{m} / \mathrm{min}$ was achieved $(10)$. 
To characterize the topography of the surfaces of the single-crystal and the sintered polycrystalline SiC, the surfaces as polished and after exposure to cavitation were examined by surface profilometry.

The stylus used was a diamond with a 2 -um radius of curvature at its tip (stylus tip width, $2 \mu \mathrm{m})$. The stylus force was $1 \mathrm{mN}(100 \mathrm{mgf})$. All surface profiles were taken at a vertical magnification of 5000 or 10000 times, and at a horizontal magnification of 100 times. The overall sensitivity of the system was calibrated by using a roughness standard with three grooves, which were nominally $0.34 \mu \mathrm{m}$ deep at the vertical magnification of 5000 and 10000 times. Ultimate sensitivity of the system was limited because the finite size of the diamond prevented penetration of the finest dents, scratches, or irregularities. However, such surface profiles could determine the dent or scratch depth to within $0.03 \mu \mathrm{m}$.

\section{RESULTS ANO DISCUSSION}

\section{Cavitation Damage}

Single-crystal SiC. - Typical examples of the surface features are shown in Fig. 2 for the single-crystal SiC $\{0001\}$ surface as polished and after exposure to cavitation in distilled water for 4 and $13 \mathrm{hr}$. No scratches or dents were evident on the polished surface of single-crystal SiC when examined by optical microscopy [Fig. 2(a)]. However, the eroded surfaces of the single-crystal SiC revealed a large number of grooves, at which the SiC was attacked more rapidly than at the other areas. Material was removed preferentially at these sites [fig. 2(b)]. The number of scratches increased with increasing exposure time to cavitation. The cavitation erosion action removed material just as does a chemical polish. The grooves remaining on the Sic surface are believed to have been highly strained areas contained in a superficial cold-worked layer, which was developed by the mechanical polishing with diamond powder. 
Typical examples of the etched surface are shown in Figs. 3 and 4 for the single-crystal SiC specimens as polished and after exposure to cavitation for $4 \mathrm{hr}$, respectively. The etched surface of the sic that had been mechanically polished showed individual etch pits and etch grooves several micrometers wide as well as deep (Fig. 3). The etched surface of the Sic exposed to cavitation for $4 \mathrm{hr}$ showed a large number of individual etch pits, two coupled etch pits, arrays of etch pits (including a spiral hexagonal depression of etch pits), and etch grooves (fig. 4). The etch pits were again several micrometers wide and deep. The individual etch pits correspond to dislocations and to defects other than dislocations, such as impurities. The two coupled etch pits correspond to dislocation half-loops developed by the application of a compressive stress due to bubble collapse during cavitation. Figure 4 also shows that there are more etch pits on the etched surface of the Sic exposed to cavitation than on that of the mechanically polished Sic.

Figure 5(a) indicates a possible mechanism for the formation of the two coupled etch pits observed. With nonmetallic crystals such as silicon carbide and tungsten carbide, which have a hexagonal close-packed crystal structure, there are several possible slip systems: $\{0001\}<11 \overline{2} 0\rangle,\{10 \overline{1} 0\}<1\} \overline{2} 0\rangle$, $\{3 \overline{3} 01\}\langle 11 \overline{2} 0\rangle$, and $\{10 \overline{1} 0\}<0001\rangle$. The first three sip systems may remain inactive, because compressive stress generated by bubble collapse on the SiC $\{0001\}$ surface during cavitation acts normal to the slip directions $\langle 11 \overline{2} 0\rangle$. However, the $\{10 \overline{1} 0\}<0001\rangle$ slip system is active [Fig. 5(a)]. The uniaxial stress concentration generated by bubble collapse during cavitation on the SiC $\{0001\}$ surface acts along the $\{10 \overline{0} 0\}$ sitip plane and in the <0001> slip direction. When the stress reaches a critical value, slip is initiated in the SiC, and a dislocation is formed.

Such dislocation can be expanded and localized in arrays with an applied stress. Figure $5($ b) indicates schematically dislocation etch pits distributed 
along close-packed $\{11 \overline{2} 0\}$ directions. This schematic resembles the spiral hexagonal depression (hexagonal arrays of etch pits) presented in Fig. 4 . The spiral depression consists of visible closely spaced individual etch pits formed in hexagonal shape. The hexagon is not concentric. Each side of the hexagon is arranged along close-packed $\{11 \overline{2} 0\}$ directions. The pitch of the spiral (spacing between successive turns of the spiral from the origin) is quite large (hundreds of nanometers), and thus the spiral is readily visible.

In addition to the spiral hexagon-shaped depression, there are a few arrays of etch pits. These arrays are also formed wherever there is a stress concentration due to bubble collapse during cavitation, by the mechanism fllustrated in Fig. 5 .

The etch groove is formed by closely spaced etch pits and is several micrometers wide as well as deep. The elastic and plastic strain energy at regions of surface damages such as scratches produced during mechanical polishing with diamond powder can cause rapid chemical attack during the etching process. The etch groove has been interpreted as being a small-angle grain boundary made up of edge dislocations, and as being several glide (slip) bands (11).

Thus, the experiment conducted established that the Sic surface deforms plastically during the cavitation erosion process and that dislocation etch pits are formed when the surface is chemically etched.

Figure 6 presents typical examples of the etched surface for the single-crystal SiC specimens as polished and after exposure to cavitation for 2, 4, and $6 \mathrm{hr}$, respectively. The etch pit density in a SiC crystal increases with an increase in exposure time to cavitation. This increase is due primarily to an increase in the amount of dislocation generated in the surficial layer of SIC. In other words, it is due to an increase in the extent of the plastic deformation of the SiC surficial iayer. At the 
beginning of the cavitation erosion process the actual damage takes place at independent small areas. However, during cavitation the damaged area spreads rapidly with increasing exposure time to cavitation. Finally, the damage takes place over the entire surface exposed to cavitation [Fig. 5(d)].

Sintered polycrystalline SiC. - Figure 7 presents surface features of the sintered polycrystalline SiC as polished and after exposure to cavitation in distilled water for $5 \mathrm{hr}$. The surface reveals two phases: a porous phase and a solid phase, which are always present on the sintered polycrystalline SiC. Initially, numerous pores of a few microns in size are distributed over the polished surface. The volume fraction of the pores present, and pore size and shape are directly affected by cavitation erosion. The number of pores per unit area (surface porosity) and the size of the pores increased with cavitation exposure (Fig. 7). Many of the SiC grains were plucked out of the SiC surface during the cavitation erosion process. For example, pores $A$ and $B$ on the polished surface [Fig. $7(a)$ ] have been changed to those of $A^{\prime}$ and $B^{\prime}$ on the eroded surface [fig. $7(b)]$, respectively.

Figure 8 presents a detalled examination of pore $A^{\prime}$ on the sintered polycrystalline SiC. This pore had been exposed to cavitation for $5 \mathrm{hr}$. The scanning electron micrograph clearly reveals fractured surfaces of the gross pore $A^{\prime}$, which were caused by the removal of SiC grains during cavitation erosion. When the SiC specimen with pore A [Fig. 8(b)] was exposed to cavitation for $15 \mathrm{~min}$, grains adjacent to pore $A$ were plucked out of the SiC surface and a fracture pit was newly produced [Fig. 8(c)]. From 15- to 60-min exposure time no further fracture was observed around pore A. At an exposure time of $90 \mathrm{~min}$, however, other grains were removed from the pore $A$ area, and as a result an enlarged fracture pit in the area adjacent to pore $A$ was observed [Fig. $8(d)]$. No further fracture was observed in the range 90 to 
$180 \mathrm{~min}$. At an exposure time of $210 \mathrm{~min}$, however, additional grains were removed from the area of pore $A[F\{\mathrm{~g} .8(\mathrm{e})]$.

\section{Surface Topography}

Because the diamond stylus has a radius of finite size at its tip, the tracing process is not an exact one, and the true surface profile cannot really be obtained. The surface profilometer, however, is a very useful tool for comparing one surface with another and for showing the differences that have taken place in the surface as a result of the process of cavitation.

Typical stylus traces are presented in Fig. 9 for the single-crystal and the sintered polycrystaliine SiC surfaces as polished and after exposure to cavitation in distilled water for $5 \mathrm{hr}$. Neither dents nor hills are evident in either of the profiles of the single-crystal sic surfaces. The profiles reveal relatively smooth surfaces [Fig. $9(a)$ ]. Figure $9(\mathrm{~b})$, however, revealed that a number of dents, which are directly related to pores such as voids and fracture pits, are present on the surfaces of sintered polycrystalline SiC.

Figure 10 presents the number of pores per unit area (pore density) as a function of exposure time to cavitation. Each value in Fig. 10 was obtained by counting the dents of ten different surface profiles. Each profile was recorded with a single pass of a diamond stylus on the SiC surfaces for a total traverse distance of $4.9 \mathrm{~mm}$.

The data of Fig. 10 indicate that essentially no detectable pores existed on the surfaces of the single-crystal SiC as polished and after exposure to cavitation at exposure times to $5 \mathrm{hr}$. In contrast, the pore density for the sintered polycrystalline SIC increased as the exposure time to cavitation increased.

The depth of all pores measured on the surface profiles for the sintered polycrystalline SiC as polished and after exposure to cavitation are presented 
in Fig. 11. The data presented for each condition of the SiC surface were obtained from the ten individual surface profiles.

The results indicate that the depth and total number of pores on the sintered polycrystalline SiC surfaces generally increased markedly with exposure to cavitation for the first $2 \mathrm{hr}$. This is in relation to those pores observed on the polished surface. After $2 \mathrm{hr}$ the total number of pores continued to increase with exposure to cavitation, but not as markedly as seen in the first $2 \mathrm{hr}$. However, no significant increase in the depth of the pores occurred with exposure to cavitation for more than $3 \mathrm{hr}$. It is interesting to note that the maximum depth of the pores on the sintered polycrystalline surfaces was approximately $7 \mu \mathrm{m}$, equivalent to the average size of the smaller diameter of the prism-shaped SiC grains $(6.9 \mu \mathrm{m})$ (table 1$)$.

\section{CONCLUSIONS}

The following conclusions were drawn from the data presented herein on the plastic deformation and fracture of single-crystal and sintered polycrystalline Sic produced by the bubble collapse of cavitation.

1. The SiC $\{0001\}$ surface can be deformed in a plastic manner during cavitation. Dislocation etch pits are formed when the surface is chemically etched. The amount of dislocation in the SiC surface increases with increasing exposure time to cavitation.

2. The presence of intrinsic defects such as voids in the surficial layers of the sintered polycrystalline SiC determine the zones from which fractured grains (debris particles) and fracture pits (pores) are generated during cavitation. The density and the average depth of pores increase with exposure to cavitation. The depth of the pores reaches an equilibrium value of $7 \mu \mathrm{m}$, which is equivalent to the average size of the smaller diameter sic grains. 
3. Single-crystal SiC has superior erosion resistance to that of sintered polycrystalline SiC.

\section{REFERENCES}

1. Buckley, D.H. and Miyoshi, K., "Friction and Wear of Ceramics," Wear, 100, pp. 333-353 (1984).

2. Hattori, S., Miyoshi, K., Buckley, D.H., and Okada, T., "Plastic Deformation of a Magnesium 0xide $\{0001\}$ Surface Produced by Cavitation," ASLE Preprint No. 86-TC-30-1, pp. 1-6 (1986).

3. Johnston, W.G., "Dislocation Etch Pits in Non-Metallic Crystals," Progress in Ceramic Science, Vol. 2., ed. by J.E. Burke, Pergamon (1962), Pp. 3-75.

4. Dufrane, K.F. and Glaeser, W.A., "Rolling-Contact Deformation of Mg0 Single Crystals," Wear. 37, pp. 21-32 (1976).

5. Faust, J.W., Jr., Tung, Y., and Llaw, H.M., "A Study of Etch Pits on Pure Polytypes of SiC," Silicon Carbide-1973, ed. by R.C. Marsha11, J.W. Faust, Jr., and C.E. Ryan, Univ. of South Carolina Press (1973), pp. $215-221$.

6. Amelinckx, S. and Strumane, G., "The Surface Features on Silicon Carbide Crystal Faces," Silicon Carbide, a High Temperature Semiconductor ed. by J.R. O'Connor and J. Smiltens, Pergamon (1960), pp. 162-201.

7. Taylor, A. and Laidler, D.S., "The Formation and Crystal Structure of Silicon Carbide," Brit. J. Appl. Phys., I. pp. 174-181 (1950).

8. Ott, H., "Structure of Carborundum (SiC)," Z. Krist, 61, pp. 515-531 (1925); and "The Lattice of Carborundum Type I," Z. Krist., 62, pp. $201-217(1926)$.

9. Hull, A.W., "The Crystal Structure of Carborundum," Phys. Rev., 13, pp. 292-295 (1919) . 
10. Faust, J.W., Jr., "The Etching of Silicon Carbide," Silicon Carbide, a High Temperature Semiconductor, ed. by J.R. O'Connor and J. Smilitens, Pergamon (1960), pp. 403-419.

11. Voge1, F.L., Pfann, W.G., Corey, H.E., and Thomas, E.E.: "Observations of Dislocations in Lineage Boundaries in Germanium," Phys. Rev., 90, pp. $489-90(1953)$. 
TABLE I. - COMPOSITION, HARDNESS, AND FRACTURE TOUGHNESS OF SiC

(a) Single-crystal $\alpha$-SiC

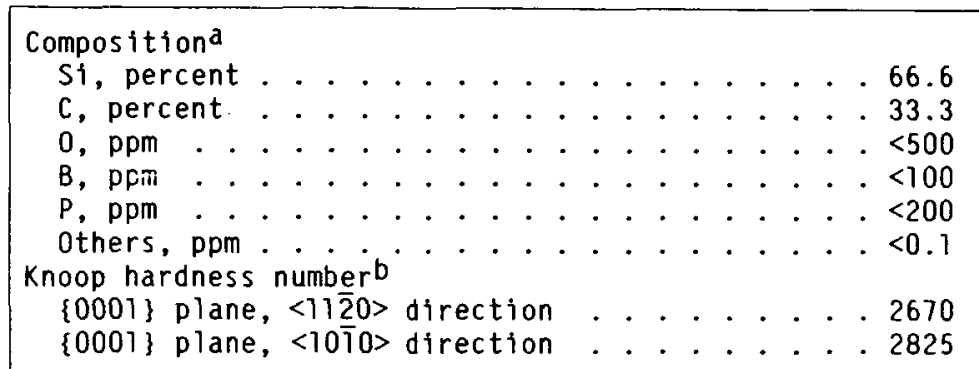

aManufacturer's analyses.

bKnoop hardness measuring load, $2.9 \mathrm{~N}$.

(b) Sintered polycrystalline SiC

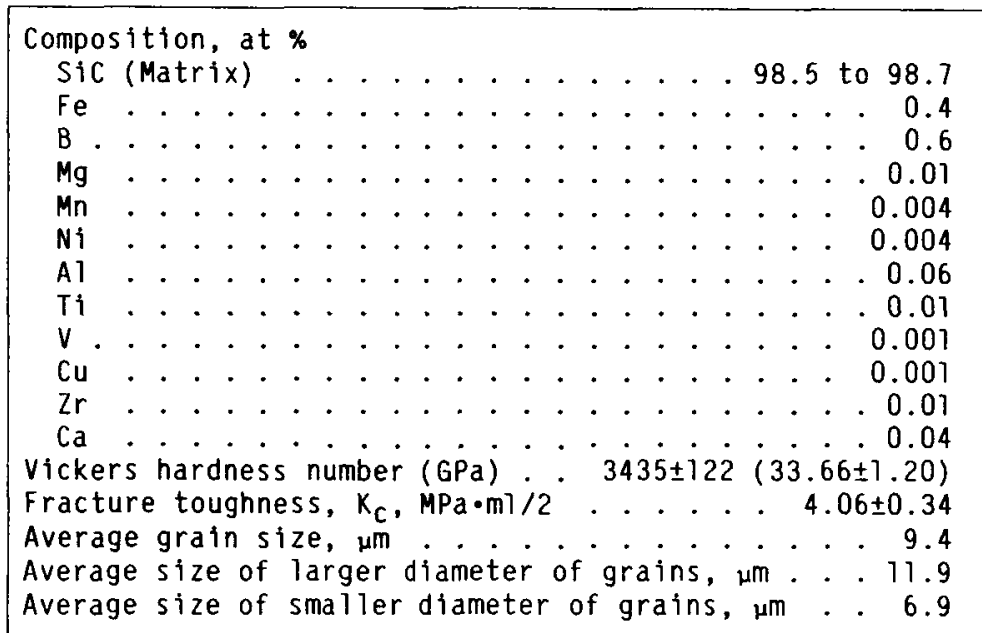




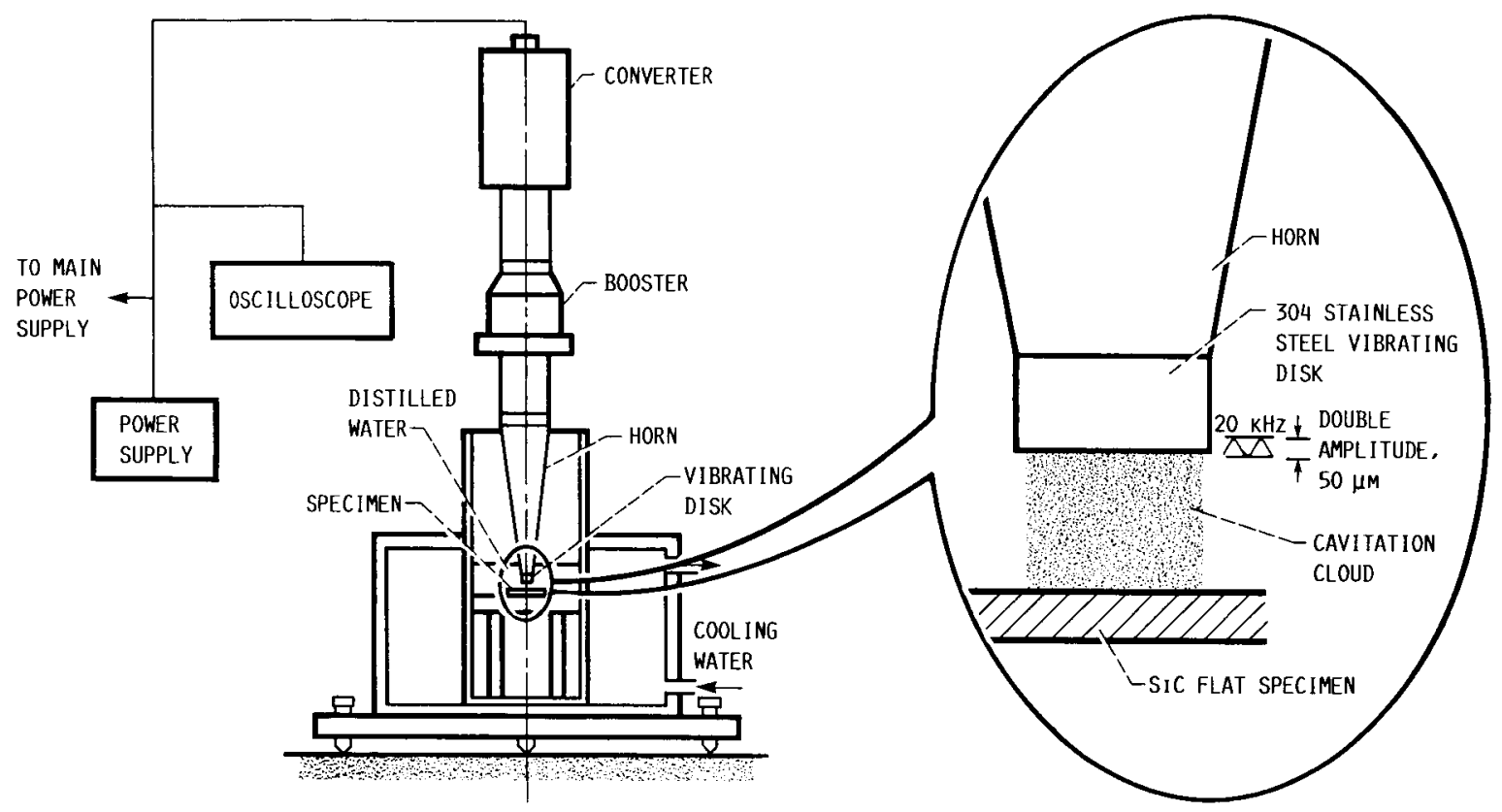

FIG. 1. - Ul.tRASONIC MAGNETOSTRICTIVE OSCILlatOR. 


\section{ORIGINAL PAGE IS OF POOR QUNTTY}
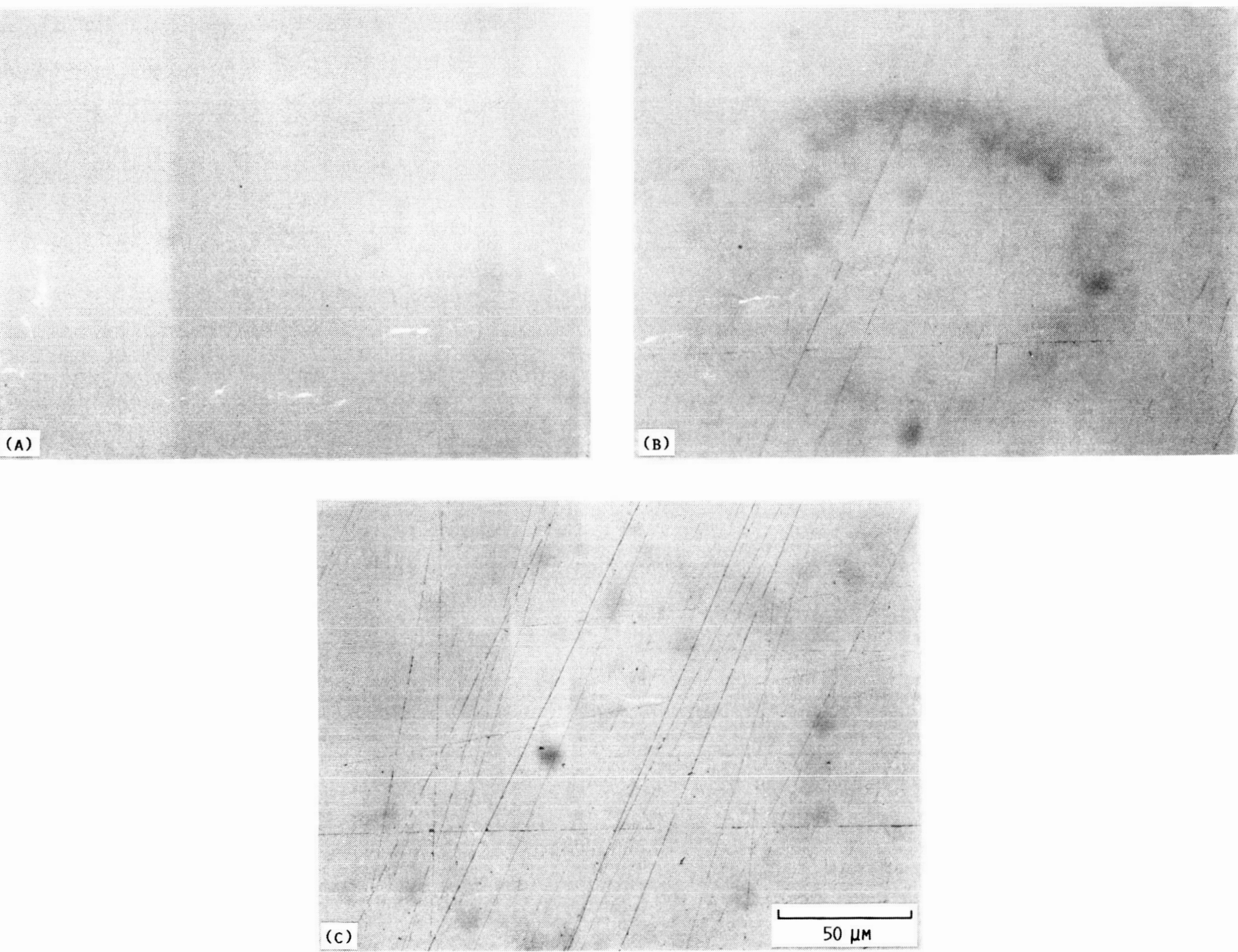

(A) SINGLE-CRYSTAL SiC SURFACE AS POLISHED.

(B) SINGLE-CRYSTAL SIC SURFACE EXPOSED TO CAVITATION FOR 4 HR IN DISTILLED WATER.

(C) SINGLE-CRYSTAL SIC SURFACE EXPOSED TO CAVITATION FOR 13 HR IN DISTILLED WATER. FIG. 2. - OPTICAL PHOTOMICROGRAPHS OF SINGLE-CRYSTAL SIC $\{0001\}$ SURFACES. 

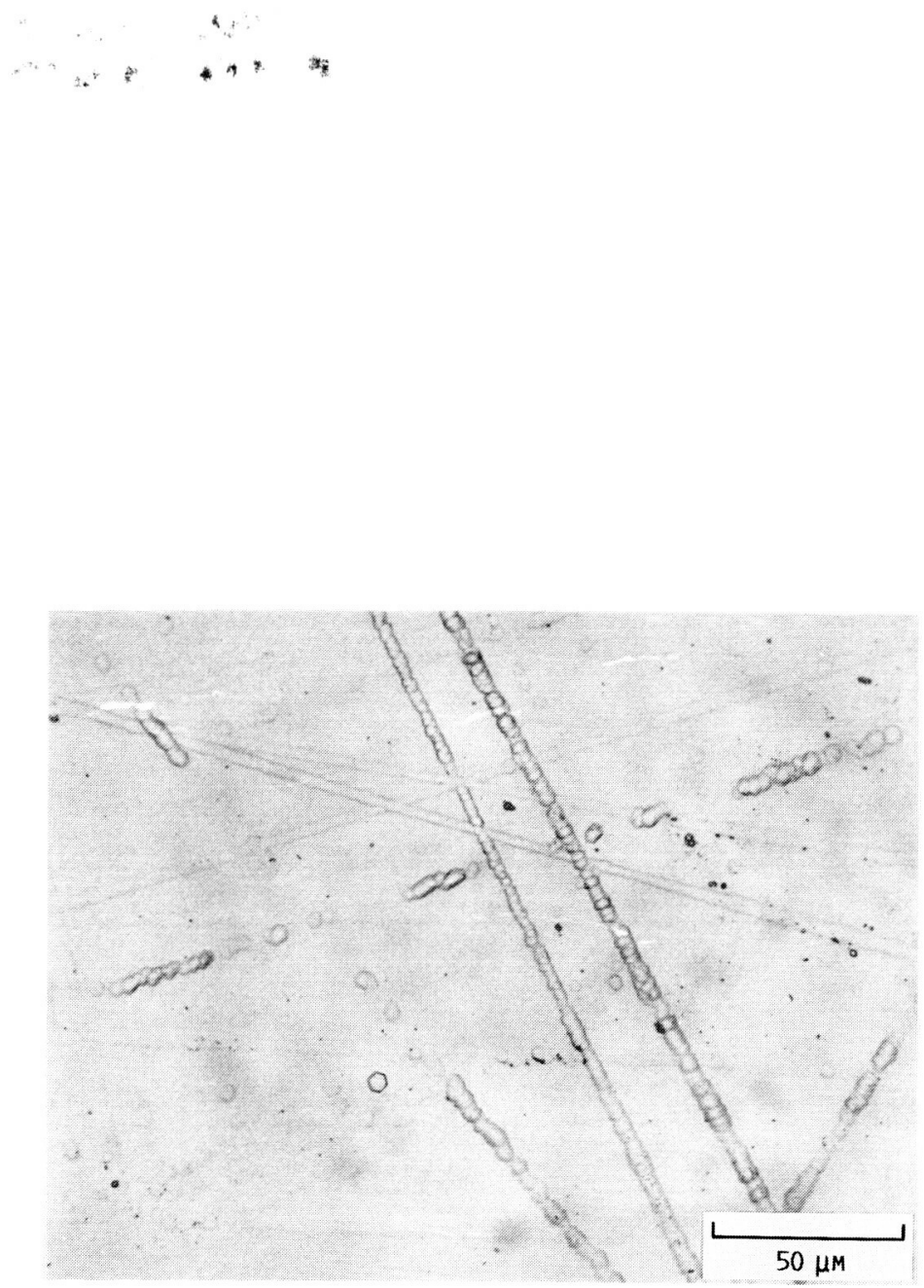

FIG. 3. - OPTICAL PHOTOMICROGRAPH OF ETCHED SURFACE OF POLISHED SIC. 


\section{ORIGINAL PAGE IS OF POOR QUALTY}

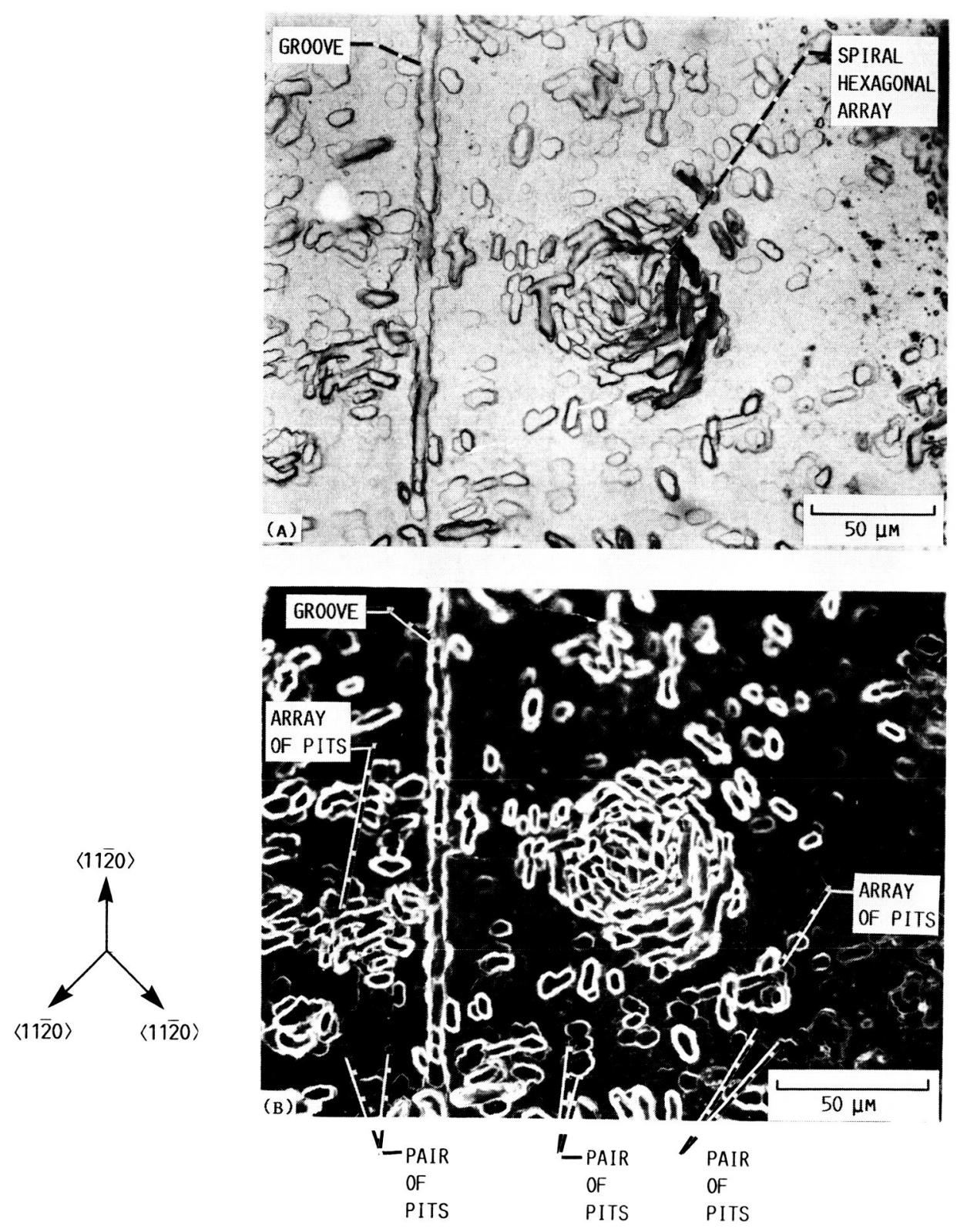

(A) BRIGHT FIELD.

(B) DARK FIELD.

Fig. 4. - OPTICAL PHOTOMICROGRAPHS OF ETCHED SURFACE OF SiC AFTER EXPOSURE TO CAVITATION FOR 4 HR. 


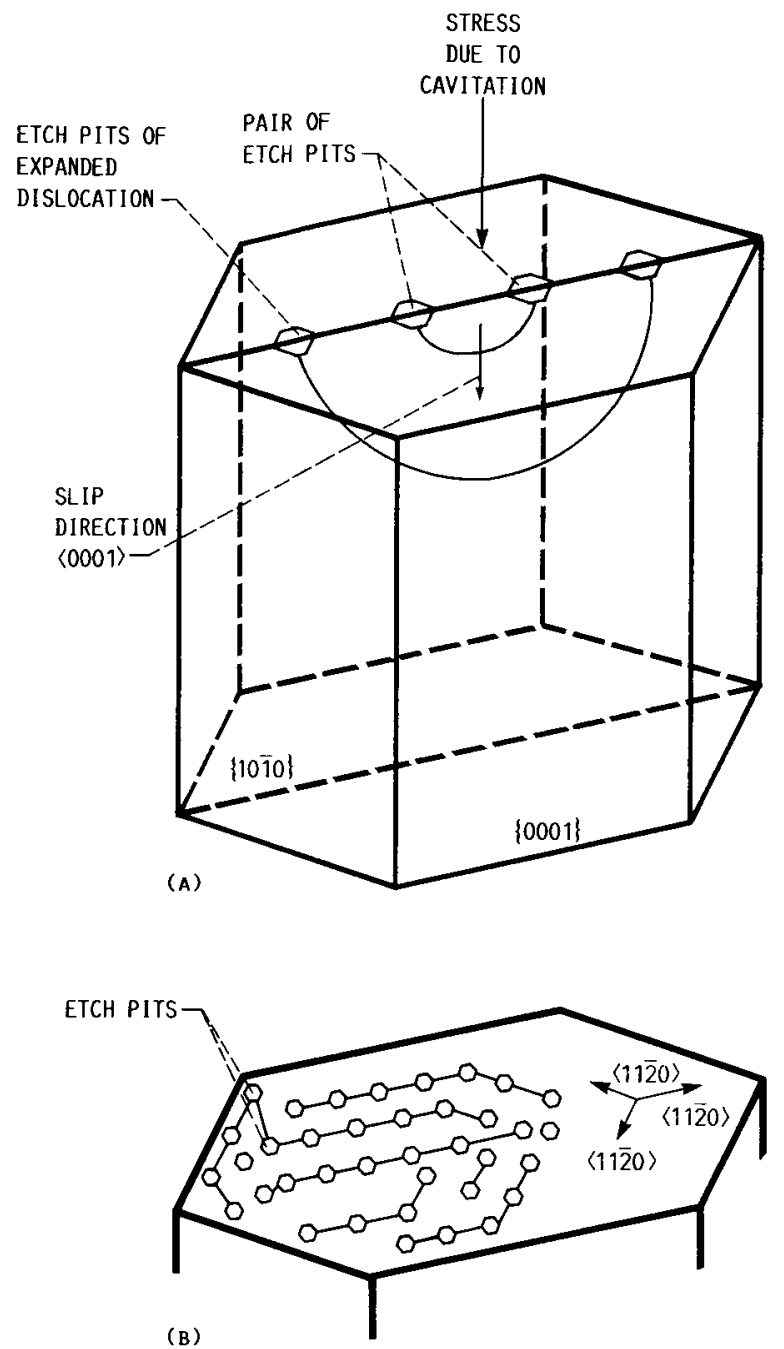

(A) A DISLOCATION HALF-LOOP AND ITS EXPANSION.

(B) ARRAYS OF DISLOCATION ETCH PITS.

Fig. 5. - GENERATION AND EXPANSION OF DISLOCATION HALFLOOPS BY APPLICATION OF A STRESS. 


\section{ORIGINAL PAGE IS
OF. POOR QUAITY}
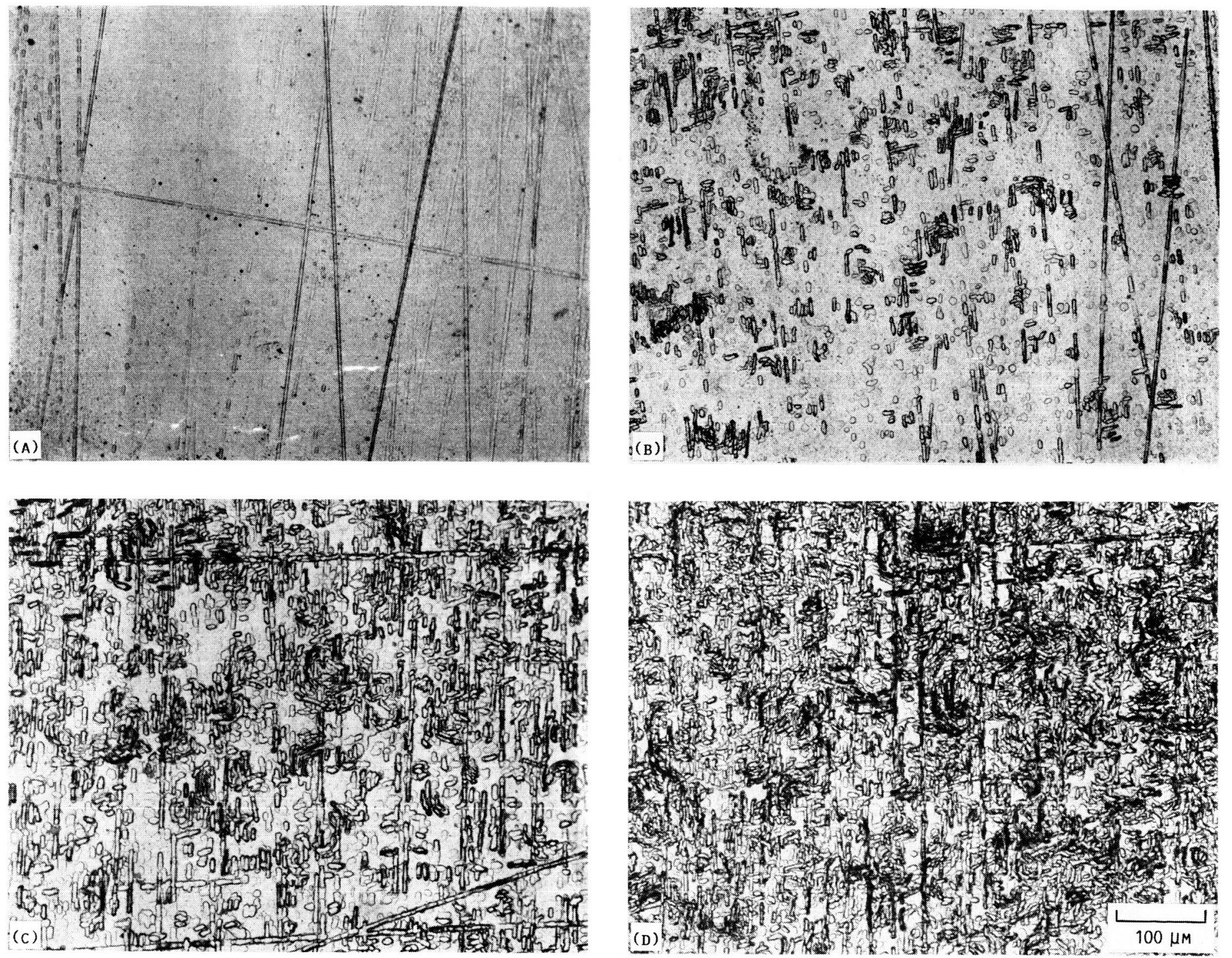

(A) ETCHED SURFACE OF POLISHED SIC.

(B) ETCHED SURFACE OF SIC AFTER EXPOSURE TO CAVITATION FOR 2 HR.

(C) ETCHED SURFACE OF SIC AFTER EXPOSURE TO CAVITATION FOR $4 \mathrm{HR}$.

(D) ETCHED SURFACE OF SIC AFTER EXPOSURE TO CAVITATION FOR 6 HR.

FIG. 6. - ETCH PITS ON SINGLE-CRYSTAL SIC $\{0001\}$ SURFACES AS POLISHED AND AFTER EXPOSURE TO CAVITATION. OPTICAL PHOTOMICROGRAPHS. 

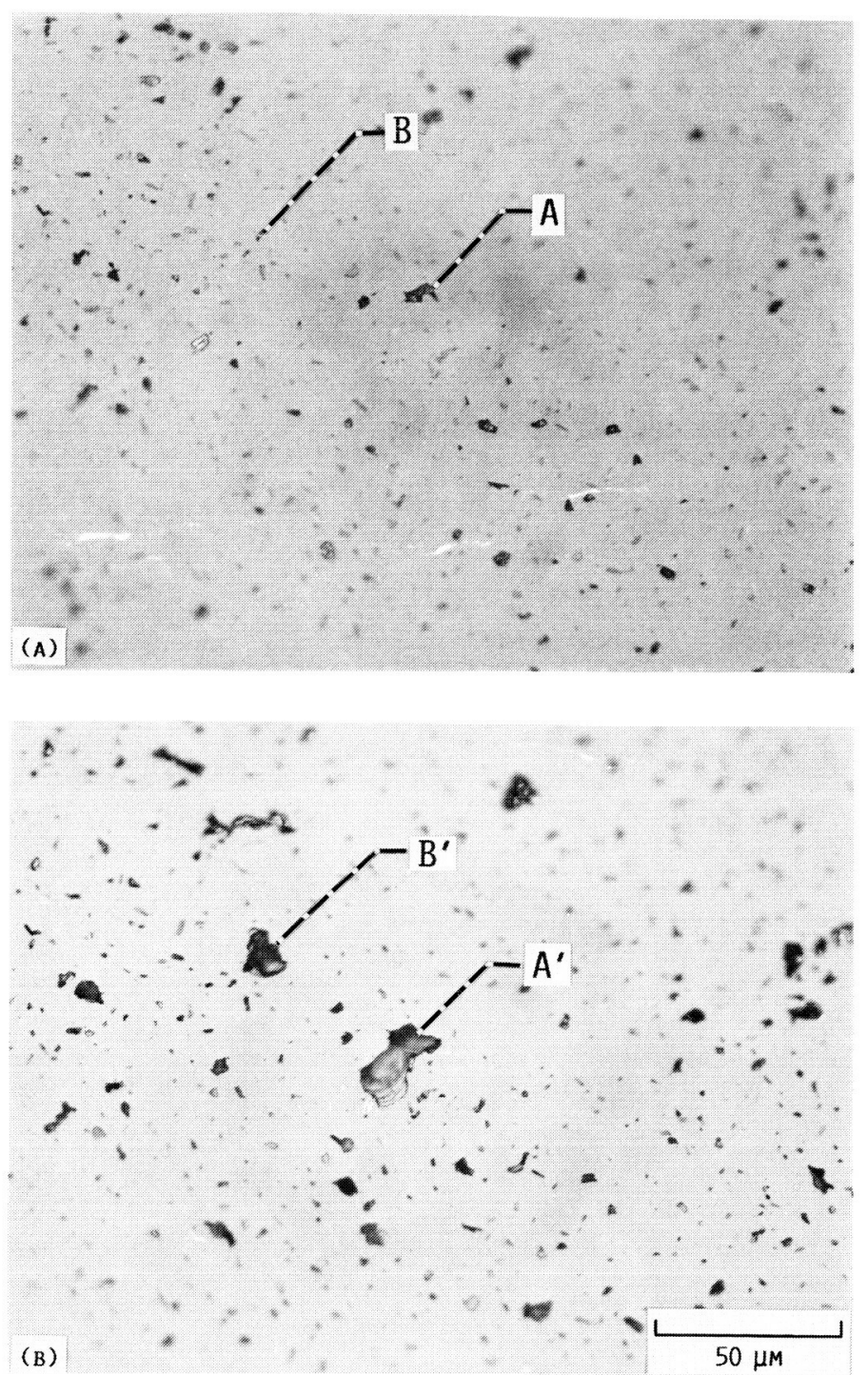

(A) SINTERED POLYCRYSTALLINE SIC SURFACE AS POLISHED.

(B) SINTERED POLYCRYSTALLINE SIC SURFACE AFTER EXPOSURE TO CAVITATION FOR 5 HR IN DISTILLED WATER.

FIG. 7. - OPTICAL PHOTOMICROGRAPHS OF SINTERED POLYCRYSTALLINE SIC SURFACES. 


\section{ORIGINAL PAGE IS \\ OF. POOR QUALTY}

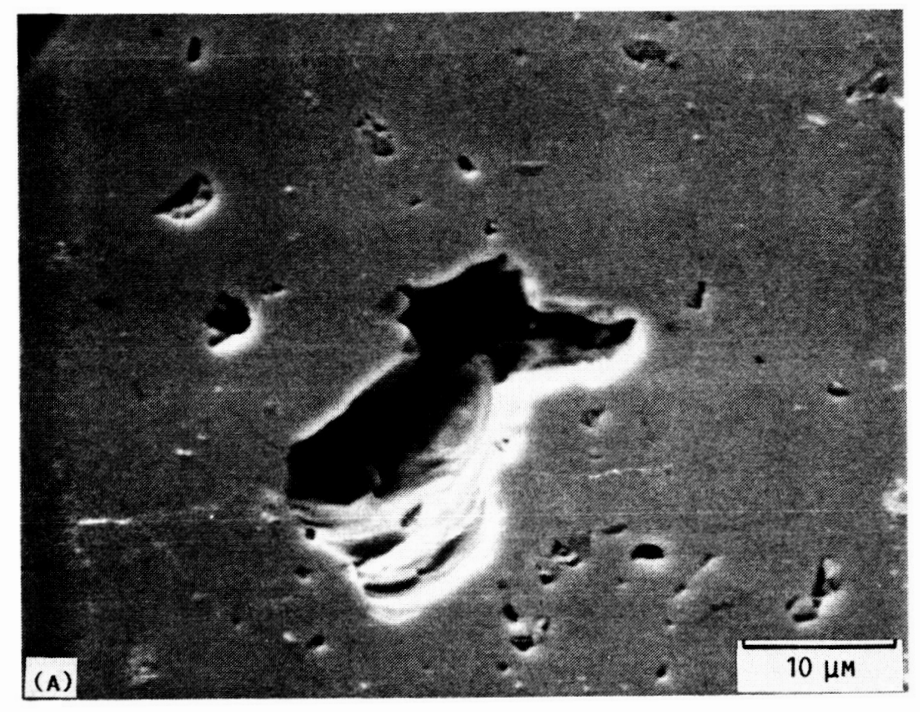

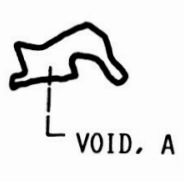

(B)

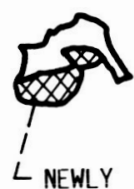

FRACTURED AREA

(c)

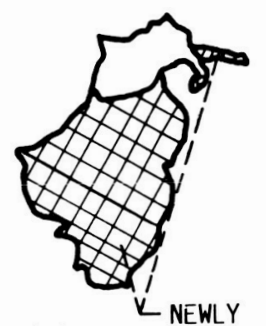

(D)
$L_{\text {NEWLY }}$ FRACTURED ( AREA

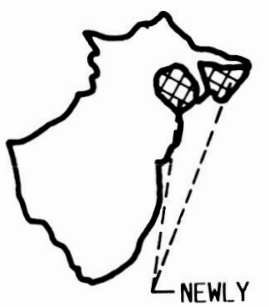

FRACTURED

(A) FRACTURE PITS AFTER EXPOSURE TO CAVITATION FOR 5 HR (300 MIN). SCANNING ELECTRON MICROGRAPH.

(B) ORIGINAL VOID, A.

(C) FRACTURE PITS AFTER EXPOSURE TO CAVITATION FOR 15 MIN TO 60 MIN.

(D) FRACTURE PITS AFTER EXPOSURE TO CAVITATION FOR 90 MIN TO 180 MIN.

(E) FRACTURE PITS AFTER EXPOSURE TO CAVITATION FOR 210 MIN TO 300 MIN.

FIG. 8. - FRACTURE PITS AND SCHEMATIC OF FRACTURE BEHAVIOR OF SINTERED POLYLCRYSTALLINE SIC AFTER EXPOSURE TO CAVITATION. 

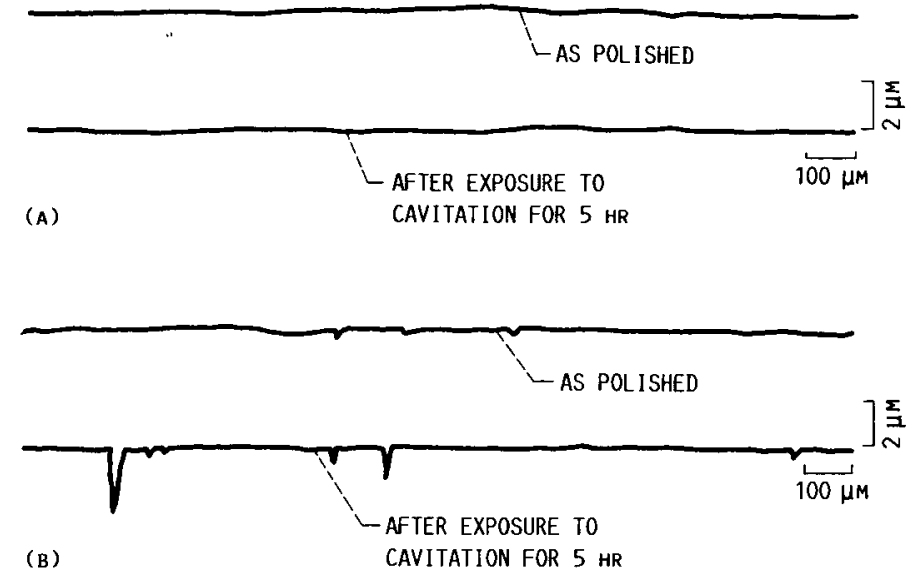

(A) SINGLE-CRYSTAL SIC.

(B) SINTERED POLYCRYSTALLINE SIC.

FI6. 9. - SURFACE PROFILES OF SIC AS POLISHED AND AFTER EXPOSURE TO CAVITATION FOR 5 HR.

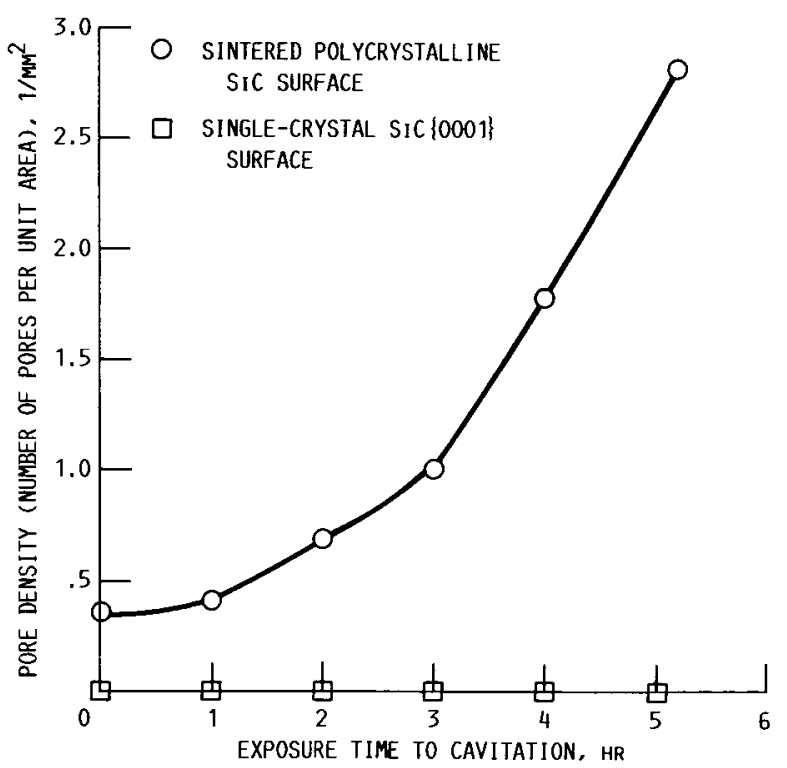

FIG. 10. - PORE. DENSITY FOR SINGLE-CRYSTAL AND SINTERED POLYCRYSTALLINE SIC SURFACES AS FUNCTION OF EXPOSURE TIME TO CAVITATION. 

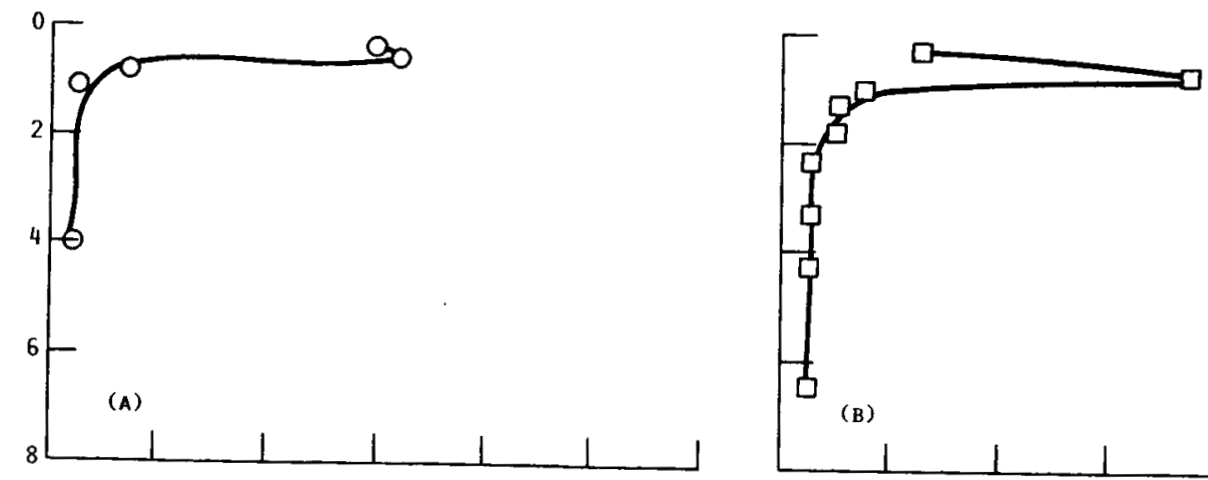

(B)
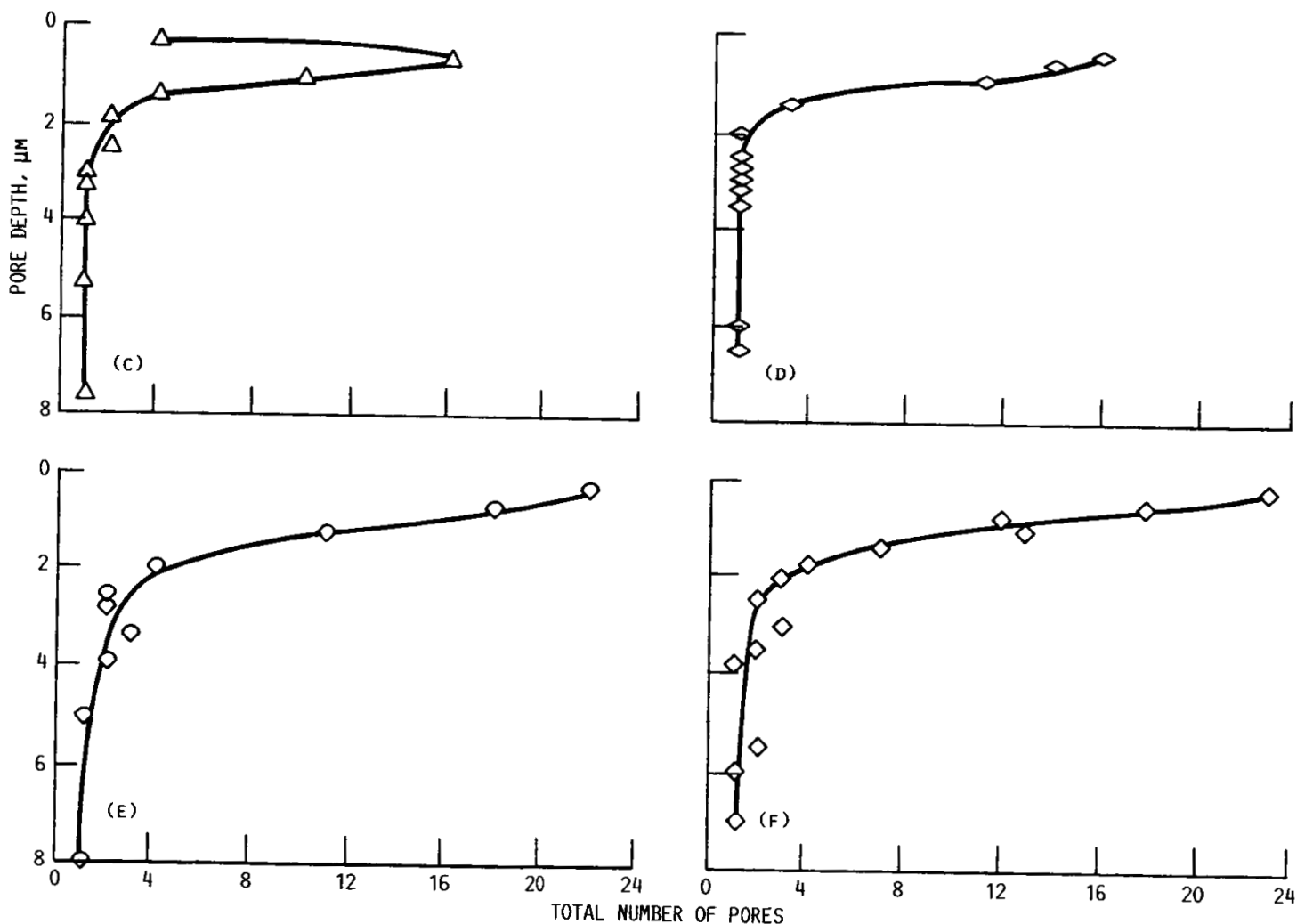

(A) AS POLISHED.

(B) EXPOSURE TIME, $1 \mathrm{HR}$,

(c) EXPOSURE TIME, 2 HR.

(D) EXPOSURE TIME, 3 HR.

(E) EXPOSURE TIME, 4 HR.

(F) EXPOSURE TIME, $5 \mathrm{HR}$.

FIG. 11. - NUMBER AND DEPTH OF PORES ON SINTERED POLYCRYSTALLINE SIC SURFACES AS POLISHED AND AFTER EXPOSURE TO CAVITATION. 


\begin{tabular}{|c|c|c|c|}
\hline $\begin{array}{l}\text { 1. Report No. } \\
\text { NASA TM-88981 }\end{array}$ & 2. Government Accession No. & \multicolumn{2}{|c|}{ 3. Recipient's Catalog No. } \\
\hline \multirow{2}{*}{\multicolumn{2}{|c|}{$\begin{array}{l}\text { 4. Title and Subtitle } \\
\text { Deformation and Fracture of Single-Crystal and } \\
\text { Sintered Polycrystalline Stlicon Carbide Produced by } \\
\text { Cavitation }\end{array}$}} & \multicolumn{2}{|l|}{ 5. Report Date } \\
\hline & & \multicolumn{2}{|c|}{$\begin{array}{l}\text { 6. Performing Organization Code } \\
506-43-11\end{array}$} \\
\hline \multirow{2}{*}{\multicolumn{2}{|c|}{$\begin{array}{l}\text { 7. Author(s) } \\
\text { Kazuhisa Miyoshi, Shuji Hattori, Tsunenori Okada, } \\
\text { and Donald H. Buckley }\end{array}$}} & \multicolumn{2}{|c|}{$\begin{array}{l}\text { 8. Performing Organization Report No. } \\
\text { E-3367 }\end{array}$} \\
\hline & & \multicolumn{2}{|l|}{ 10. Work Unit No. } \\
\hline \multicolumn{2}{|c|}{$\begin{array}{l}\text { 9. Performing Organization Name and Address } \\
\text { National Aeronautics and Space Administration } \\
\text { Lewis Research Center } \\
\text { Cleveland, Ohio } 44135\end{array}$} & \multicolumn{2}{|c|}{ 11. Contract or Grant No. } \\
\hline \multirow{2}{*}{\multicolumn{2}{|c|}{$\begin{array}{l}\text { 12. Sponsoring Agency Name and Address } \\
\text { National Aeronautics and Space Administration } \\
\text { Washington, D.C. } 20546\end{array}$}} & \multicolumn{2}{|c|}{$\begin{array}{l}\text { 13. Type of Report and Period Covered } \\
\text { Technical Memorandum }\end{array}$} \\
\hline & & \multicolumn{2}{|c|}{ 14. Sponsoring Agency Code } \\
\hline \multicolumn{4}{|c|}{$\begin{array}{l}\text { 15. Supplementary Notes } \\
\text { Prepared for the } 1987 \text { Joint Tribology Conference, cosponsored by the American } \\
\text { Society of Lubrication Engineers and the American Society of Mechanical } \\
\text { Engineers, San Antonio, Texas, October 5-8, } 1987 \text {. K. Miyoshi, NASA Lewis } \\
\text { Research Center; S. Hattori and T. Okada, Fukui University, Fukui, Japan; } \\
\text { D.H. Buckley, Case Western Reserve University, Cleveland, Ohio } 44106 \text {. }\end{array}$} \\
\hline \multicolumn{4}{|c|}{$\begin{array}{l}\text { 16. Abstract } \\
\text { An investigation was conducted to examine the deformation and fracture behavior } \\
\text { of single-crystal and sintered polycrystalline SiC surfaces exposed to cavita- } \\
\text { tion. Cavitation erosion experiments were conducted in distilled water at } 25^{\circ} \mathrm{C} \\
\text { by using a magnetostrictive oscillator in close proximity (1 mm) to the surface } \\
\text { of sic. The horn frequency was } 20 \mathrm{kHz} \text {, and the double amplitude of the vibrating } \\
\text { disk was } 50 \mu \mathrm{m} \text {. The results of the investigation indicate that the SiC \{0001\} } \\
\text { surface could be deformed in a plastic manner during cavitation. Dislocation } \\
\text { etch pits were formed when the surface was chemically etched. The number of } \\
\text { defects, including dislocations in the sic \{0001\} surface, increased with } \\
\text { increasing exposure time to cavitation. The presence of intrinsic defects such } \\
\text { as voids in the surficial layers of the sintered polycrystalline sic determined } \\
\text { the zones at which fractured grains and fracture pits (pores) were generated. } \\
\text { Single-crystal sic had superior erosion resistance to that of sintered poly- } \\
\text { crystalline sic. }\end{array}$} \\
\hline $\begin{array}{l}\text { 17. Key Words (Suggested by Authorl } \\
\text { Silicon carbide } \\
\text { Cavitation } \\
\text { Deformation }\end{array}$ & $\begin{array}{l}\text { 18. Distributions } \\
\text { Unc lassi } \\
\text { STAR Cat }\end{array}$ & $\begin{array}{l}\text { dent } \\
\text { ry } 27\end{array}$ & \\
\hline $\begin{array}{l}\text { 19. Security Classif. (of this report) } \\
\text { Unc lass if ied }\end{array}$ & $\begin{array}{l}\text { 20. Security Classif. (of this page) } \\
\text { Unc lass if ied }\end{array}$ & $\begin{array}{c}\text { 21. No. of pages } \\
24\end{array}$ & $\begin{array}{r}\text { 22. Price" } \\
\text { A02 }\end{array}$ \\
\hline
\end{tabular}

"For sale by the National Technical Information Service, Springfield, Virginia 22161 